\title{
TEN YEARS OF EXPERIENCE WITH THE MODIFIED ROSS PROCEDURE
}

Paul Stelzer, MD

Susanne Weinrauch, MD

Robert F. Tranbaugh, MD

\begin{abstract}
Background: To assess the full root modification of the Ross procedure, we examined operative and long-term results. Methods: We retrospectively reviewed 145 patients (118 men and 27 women) operated on from March 1987 through April 1997. Ages ranged from 17 to 68 years. Primary diagnosis was aortic stenosis in 43 patients $(29.6 \%)$ and aortic regurgitation in 62 patients $(42.8 \%)$. There was mixed disease (stenosis and regurgitation) in 40 patients $(29.6 \%)$ of whom the vast majority had predominant stenosis. Results: Early death was 7 of 145 patients $(4.8 \%)$. Twelve patients had 14 significant complications $(8.5 \%)$. There were four late deaths. Overall patient survival is $90.5 \% \pm 3.1 \%$ at 5 years and $84.5 \%$ $\pm 14.1 \%$ at 7 years. Endocarditis occurred in three patients-two on the autograft and one on the pulmonary homograft. Three patients had cerebrovascular accidents. In 5 of 132 patients $(3.8 \%)$ reoperations were required on the autograft. Freedom from autograft reoperation was $93.9 \%$ $\pm 3.1 \%$ at 5 years and $88.6 \% \pm 6.4 \%$ at 7 years. Echocardiographic follow-up reveals more than mild aortic regurgitation in only nine patients, including the five patients in whom reoperations were required. Seven of 11 patients with active endocarditis at the time of the operation had adverse outcomes. Conclusions: Ten years' experience with the modified Ross procedure has shown excellent results with regard to short- and long-term morbidity and death. It is the procedure of choice for young patients who need aortic valve replacement but should be used with caution in the setting of active endocarditis. (J Thorac Cardiovasc Surg 1998;115:1091-100)
\end{abstract}

In March 1967, Donald Ross ${ }^{1}$ reported the first pulmonary autograft replacement of the aortic valve. His remarkable work clearly established the procedure as an extremely important option for patients with aortic valve disease. He found, however, that reoperation was ultimately necessary in 38 of 314 patients $(12 \%)$ because of either endocarditis or "technical incompetence" of the autograft valve. ${ }^{2}$ In efforts to improve the competency rate, Ross modified his original freehand subcoronary technique to a "cylinder" technique in 1976 but still met with a significant failure rate. On the basis of Ross's pioneering work with aortic homografts and his

From the Division of Cardiac Surgery, Beth Israel Medical Center, New York City, N.Y.

Received for publication July 8, 1997; revisions requested Sept. 3, 1997; revisions received Oct. 10, 1997; accepted for publication Dec. 3, 1997.

Address for reprints: Paul Stelzer, MD, Division of Cardiac Surgery, Beth Israel Medical Center, 317 East 17th St., 11th Floor, New York City, NY 10003.

Copyright (C) 1998 by Mosby, Inc.

$0022-5223 / 98 \$ 5.00+0 \quad \mathbf{1 2 / 6 / 8 8 0 0 8}$ observation that when used as a full root replacement, the aortic homograft valve was "invariably competent,"3 one of us (P.S.) postulated that the same might be true for the pulmonary autograft. The Ross procedure was thus modified to a full root replacement 10 years ago to decrease the need for reoperation. The technique has been previously described. ${ }^{4-6}$ We have retrospectively reviewed the outcome of 145 consecutive patients who underwent the modified Ross procedure to define the results of autograft root replacement and to provide as much long-term follow-up as possible, focusing on the incidence of significant autograft regurgitation and need for reoperation.

\section{Patients and methods}

Patient population. From March 1987 through April 1997, 145 patients underwent aortic valve and root replacement with the pulmonary autograft (modified Ross procedure) with a single (P.S.) responsible surgeon. There were 118 men and 27 women. Age ranged from 17 to 68 years, with a mean of 43.1 years. The primary diagnosis was aortic stenosis (AS) in 43 patients $(29.6 \%)$ and aortic regurgitation $(\mathrm{AR})$ in 62 patients $(42.8 \%)$. There was 
Table I. Previous cardiac surgery

\begin{tabular}{cl}
\hline $\begin{array}{c}\text { No. of patients } \\
(n=17)\end{array}$ & \multicolumn{1}{c}{ Type of procedure } \\
\hline $8^{*}$ & Previous aortic valve repair \\
1 & Aortic valve repair/mitral valve repair \\
5 & Aortic valvotomy \\
2 & Ventricular septal defect repair \\
1 & $\begin{array}{l}\text { Repair of coarctation and patent } \\
\text { ductus arteriosus }\end{array}$ \\
\end{tabular}

*One patient underwent two previous AVRs.

combined disease (AS/AR) in 40 patients $(29.6 \%)$ of which most had predominant AS (36 of 40 patients). Table I shows the 18 previous cardiac operations done on 17 patients. There were 21 patients $(14.5 \%)$ with an endocarditis history-11 patients with active endocarditis and 10 with healed endocarditis. Ten of the 11 active cases and eight of the 10 healed cases involved native valves $(85.7 \%)$; only three cases involved prosthetic valves. Concomitant procedures were performed in 36 patients $(24.8 \%)$. There were 14 mitral procedures and 12 coronary bypass procedures ranging from one to five grafts (mean 2.2 grafts). Other procedures included subaortic resections $(n=3)$ and ascending aneurysm repairs $(n=$ 3 ), as shown in Table II.

Technique. All patients underwent the operation with standard techniques of cardiopulmonary bypass with cold cardioplegia (primarily blood and mostly retrograde) with moderate systemic hypothermia $\left(30^{\circ}\right.$ to $32^{\circ} \mathrm{C}$ ). Initial size estimates in recent experience have been obtained with intraoperative transesophageal echocardiography. The aortic anulus is estimated by measuring from the interventricular septum to the hinge point of the anterior mitral leaflet in the long axis, and the pulmonary anulus is measured in the short axis. The aortic dimension thus obtained is fairly accurate, but difficulties imaging the proximal pulmonary trunk make this less reliable.

Before the pulmonary trunk is harvested, the aortic valve is excised and root measurements are made at the level of the anulus with standard circular or cylindrical sizers typically used for mechanical valve operations. The pulmonary artery is divided just proximal to the bifurcation leaving the anterior wall longer than the posterior. The adventitia is preserved intact as much as possible; a 4 to $5 \mathrm{~mm}$ muscle cuff is kept on the proximal end, and the first septal perforator is protected posteriorly. The excised autograft is supported gently on the proximal end with a forceps at each commissure, and the same cylindrical sizers are used to measure the inside diameter without any stretching of the anulus.

If the aortic root is more than $2 \mathrm{~mm}$ smaller than the pulmonary (a rare situation), dividing the commissure between the left and the noncoronary sinuses can enlarge the root. On one occasion, annular hypoplasia and subaortic stenosis required enlarging the root by a modified Konno technique with extensive septal muscle excision, seating the autograft down in the widened outflow tract. Usually, in AS, the pulmonary anulus is just slightly larger
Table II. Concomitant procedures

\begin{tabular}{cl}
$\begin{array}{c}\text { No. of patients } \\
(n=36)\end{array}$ & \multicolumn{1}{c}{ Concomitant procedure } \\
\hline 12 & Coronary artery bypass \\
13 & Mitral valve repair \\
1 & Mitral valve replacement \\
3 & Septal myomectomy/resection \\
& subaortic membrane \\
3 & Aortic graft \\
1 & Closure of aortoatrial fistula \\
1 & Patent ductus arteriosus ligation \\
1 & Ventricular septal defect closure \\
1 & Repair septal aneurysm \\
\hline
\end{tabular}

than the aortic anulus and fits nicely without tailoring. In cases of primary regurgitation, the aortic anulus may be considerably dilated; this must be addressed. The commissures can be plicated down on either side of the noncoronary sinus to reduce the anulus 4 to $5 \mathrm{~mm}$, but a discrepancy of over $10 \mathrm{~mm}$ is considered a contraindication to the procedure. With or without the plication, the regurgitant anulus should be supported with a strip of Teflon felt (5 to $7 \mathrm{~mm}$ wide), which is measured to length around a sizer one size larger than the internal diameter of the autograft. This strip is incorporated in the proximal suture line of continuous 4-0 polypropylene placed at the level of the anulus.

The aorta was transected completely in all but one case, and the coronary arteries were mobilized with buttons of aortic wall. (In that one case the left main was kept as a "wagon tongue" on the distal aorta by carrying the line of aortic transection down into the sinus below the ostium.) The coronary buttons were then reimplanted with continuous 6-0 polypropylene. The distal autograft-aortic suture line was constructed with continuous 4-0 polypropylene. If the distal aorta was dilated, it was either gathered and supported with another felt strip and/or reduced with a lateral wedge aortorrhaphy to appropriate size. Finally, the right ventricular outflow tract (RVOT) was reconstructed. All but four of these were done with cryopreserved pulmonary homograft conduits.

Concomitant procedures were done first to ensure that mitral valves, for example, could be repaired before proceeding with the autograft harvest. Coronary artery bypass grafting was done with the left internal thoracic artery and recently, the radial artery, in most of the operations in keeping with the objective of the Ross procedure to maximize benefit for the longest possible time without reoperation.

Follow-up. Patients and/or their physicians were contacted for clinical outcome. Echocardiographic data were obtained whenever available. Such echocardiographic data were available for 96 patients, but clinical follow-up was $95 \%$ complete spanning 345 patient-years with only seven patients lost to follow-up. Kaplan-Meier analysis was used to determine event-free survival curves. Data were analyzed with SAS software (SAS, Inc., Cary, N.C.) and plotted using SPSS software (SPSS, Inc., Chicago, Ill.). 
Table III. Operative morbidity

\begin{tabular}{cl}
$\begin{array}{c}\text { No. of patients } \\
(n=12)\end{array}$ & \multicolumn{1}{c}{ Complication } \\
\hline 4 & Hemorrhage requiring reoperation \\
3 & Heart block requiring permanant pacemaker \\
1 & Deep sternal wound infection \\
2 & Combined renal and respiratory failure \\
1 & Isolated respiratory failure \\
1 & Right ventricular failure necessitating \\
& delayed closure of chest \\
\hline
\end{tabular}

\section{Results}

Four of 145 patients (2.8\%) died in the hospital, and three others died within 6 weeks of discharge, for a total early mortality of $4.8 \%$. Three deaths were in the first 15 patients and four in the subsequent 130 patients. Of the first three deaths, two were caused by bleeding problems in the setting of endocarditis and the other was the result of a pulmonary embolus 2 weeks after discharge. Of the last four deaths, two resulted from right ventricular failure caused by infarction from coronary diseaseone unrecognized and one ungraftable, and the other two were caused by arrhythmias. One patient died at home just over 5 weeks after the operation. The other was receiving anticoagulants for persistent atrial fibrillation; a symptomatic pericardial effusion developed, and arrest occurred 6 weeks after the original operation with induction of anesthesia for drainage of that effusion. He could not be resuscitated despite heroic efforts.

Table III lists the 14 major complications that occurred in 12 patients $(8.5 \%)$. Bleeding required reoperation in four patients. Respiratory insufficiency affected three patients, two of whom had transient renal failure that contributed to the prolonged ventilator requirement. Neither of these required long-term dialysis. Three patients with extensive annular calcification had persistent heart block that required permanent pacing; one of these patients had extensive subaortic stenosis resected as well.

Overall patient survival is shown with the KaplanMeier analysis in Fig. 1 with $90.5 \% \pm 3.1 \%$ at 5 years and $84.5 \% \pm 14.1 \%$ at 7 years. There were four late deaths as listed in Table IV. Two deaths were cardiac related, one sudden and presumed to be caused by arrhythmias and one caused by a myocardial infarction. Two patients died of pulmonary malignancies at 6 months and $2 \frac{1}{2}$ years, respectively. The two patients with lung cancer had nor-
Table IV. Late death $(n=4)$

\begin{tabular}{cl}
\hline $\begin{array}{c}\text { Time interval since hospital } \\
\text { discharge (mo.) }\end{array}$ & \multicolumn{1}{c}{ Cause of death } \\
\hline 6.5 & Cancer \\
24 & Sudden death \\
32 & Cancer \\
86 & Myocardial infarction \\
\hline
\end{tabular}

mally functioning autograft valves, but one of the two dying a cardiac death had moderate AR and the other had moderately severe AR.

Endocarditis occurred in three patients-two on the autograft (at 12 and 68 months, respectively) and one on the pulmonary homograft (two episodes, at 24 and 36 months in the same intravenous drug abuser). The Kaplan-Meier freedom from endocarditis is $97.2 \% \pm 1.9 \%$ at 5 years and $92.8 \% \pm 4.7 \%$ at 7 years (Fig. 2).

Three patients had cerebrovascular accidents (CVAs). One patient with systemic lupus erythematosus and the anti-cardiolipin antibody syndrome had two CVAs at 3 and 5 months after the operation with a normally functioning valve. There was no documented arrhythmia or clot in the heart on echocardiography. This patient is the only one who has been receiving anticoagulants. Two other patients had CVAs at 70 and 90 months, respectively, again with normal echocardiograms. These two patients were both over 60 years of age at the time of the CVA. Kaplan-Meier freedom from thromboembolic events at 5 years is $99.2 \% \pm 0.8 \%$ and at 7 years is $93.1 \% \pm 5.5 \%$, as shown in Fig. 3 .

Six patients required additional cardiac surgery. One patient needed mitral valve replacement 3 years after combined mitral commissurotomy and Ross procedure. Five patients required autograft valve replacement for regurgitation. Two of these patients had endocarditis, and three patients had technical failure. The technical failure in one patient at 9 months was due to a judgment error, use of an autograft with myxomatous degeneration and big, floppy leaflets. The patient had significant AR from the outset despite efforts to tether these leaflets at the commissures. The second technical failure probably also represents imperfect initial reconstruction with moderate AR documented on repeat catheterization before discharge, ultimately leading to reoperation for moderately severe AR 6 years later. The other technical failure was in a patient with inflammatory root disease of an ill-defined cause. Appropriate felt-strip support of the anulus was not used, 


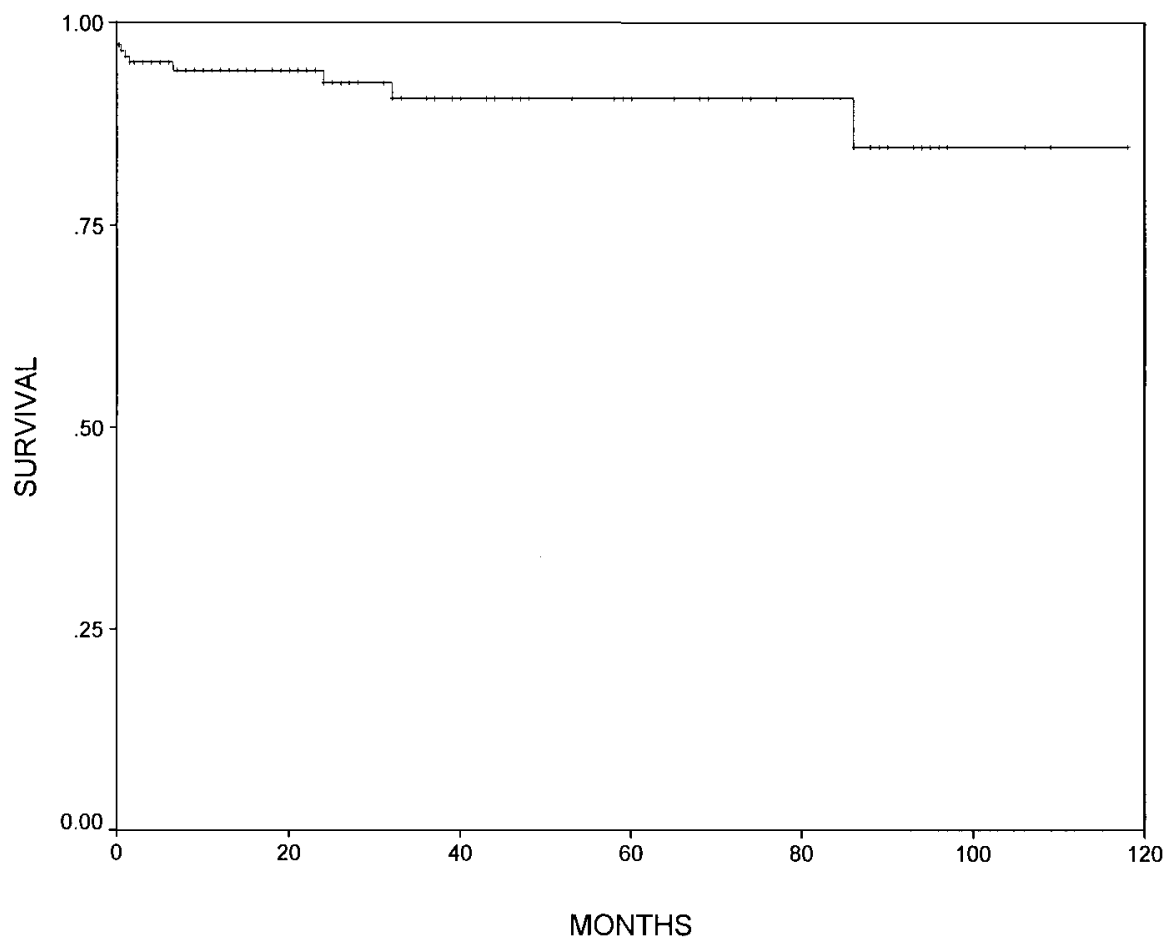

Fig. 1. Kaplan-Meier patient survival.

and significant regurgitation became apparent at 1 year. He had a valve replacement at 5 years when class II symptoms developed. The two patients with endocarditis underwent repeat root replacement with cryopreserved aortic homografts. The three technical failures had mechanical valves placed within the previous autograft root. All did well. Kaplan-Meier freedom from autograft reoperation was $93.9 \% \pm 3.1 \%$ at 5 years and $88.6 \% \pm 6.4 \%$ at 7 years (Fig. 4).

When including death, reoperation, CVA, and endocarditis as events, the event-free survival at 5 years is $82.7 \% \pm 5.1 \%$ and at 7 years is $74.2 \% \pm$ 7.4\% (Fig. 5).

Echocardiographic information on the 38 patients who underwent operation within the last year is only immediate postoperative data. There are 26 echocardiograms for 1- to 2-year follow-up, 16 for 2- to 5-year follow-up, and 16 for more than 5-year follow-up. Both early and late echocardiographic follow-up of these patients reveal a notable and consistent absence of any significant gradients across the autograft valve. A tiny central jet of AR is commonly seen (Fig. 6), but more than mild AR was seen in only nine patients in this series, seven of whom had preoperative AR. Five of the nine pa- tients underwent reoperations as previously described. One died suddenly 2 years after the operation; one died of a myocardial infarction 7 years after the operation; two others are asymptomatic, including one who recently was delivered of a healthy baby after an uneventful pregnancy. With the current technique of annular support, of 45 recent studies done early after the operation, 9 were read as "no AR," 14 as "trace AR," 19 as "mild AR," 2 as "mild to moderate AR," and only 1 "moderate AR."

\section{Discussion}

Our 10-year experience with the autograft root replacement, the modified Ross procedure, clearly confirms the original hypothesis that autograft root replacement would result in a very low rate of reoperation. The modified Ross procedure maintains the anatomy and the three-dimensional geometry of the autograft. This results in a more consistently competent autograft valve compared with the intraaortic techniques of subcoronary implantation or inclusion root. Reoperation on the autograft was necessary in only 5 of 132 patients $(3.8 \%)$ in this series as opposed to $12 \%$ to $16 \%$ in series heavily weighted to the subcoronary and intraaortic cylinder 


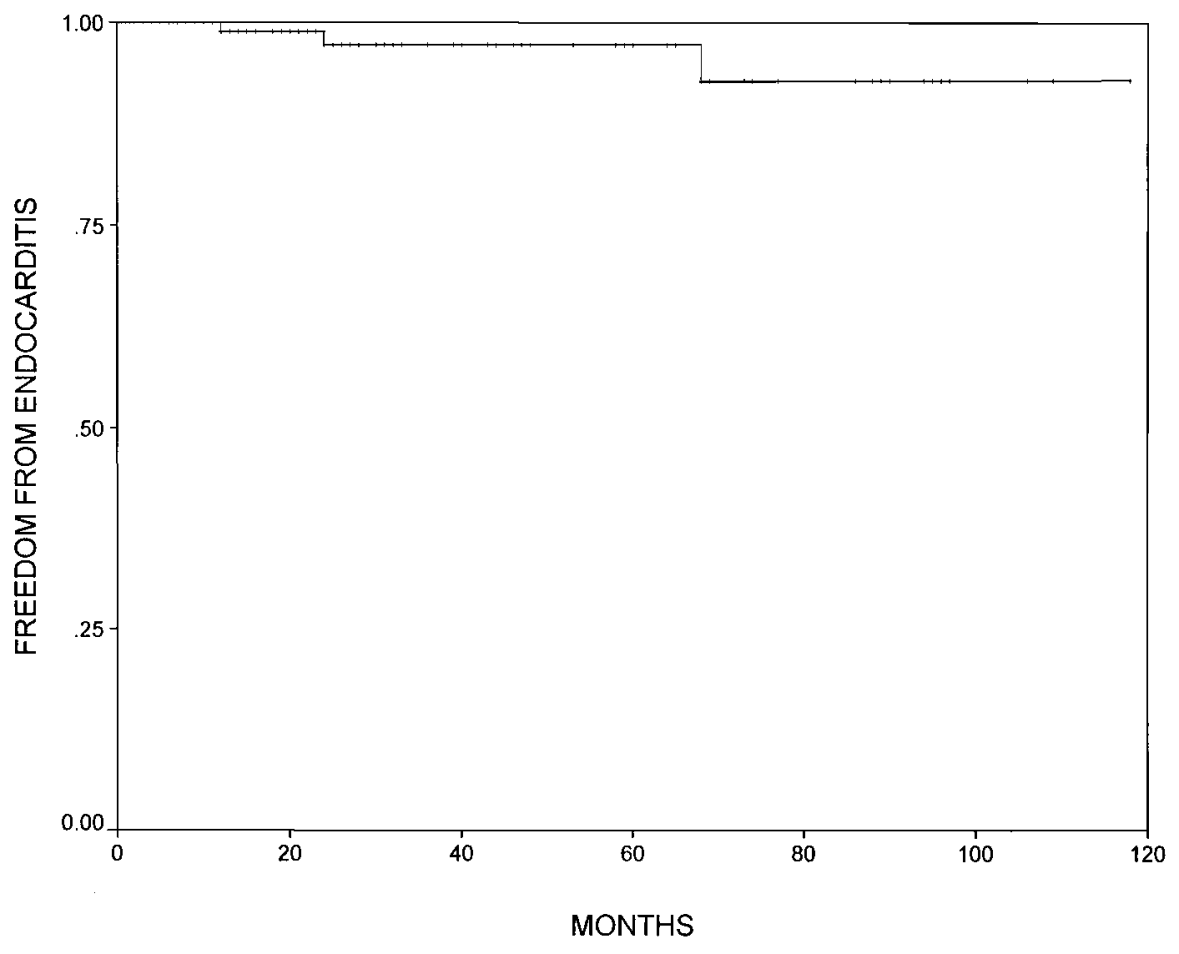

Fig. 2. Kaplan-Meier freedom from endocarditis.

techniques., 2,7 Of note is the fact that all have survived reoperation without incident. Our study supports the study of Elkins and associates, ${ }^{8}$ who demonstrated a significant advantage of the full root over the cylinder and the subcoronary technique with severe AR and reoperation as criteria. They found an autograft reoperation rate of $3.3 \%$ (4 of 122 patients) in the root replacement group compared with $6.9 \%$ (4 of 58 patients) and $11.5 \%$ (3 of 26 patients) in the groups with cylinder and subcoronary implantation, respectively.

As experience with the Ross procedure has increased and operative death and early technical failure have decreased, there has been more general acceptance of the autograft root replacement. Root replacement is reported to be the primary technique in $71 \%$ of the patients who undergo the Ross procedure as recorded in the Ross Procedure International Registry. 9 An increasing number of surgeons $^{8,10-13}$ have reported favorably on this technique. Of particular significance is the increasingly high percentage of full root replacements done by Ross himself. ${ }^{14,15}$

The modified Ross procedure does sacrifice the advantage of closing the native aorta over the autograft. The death of two patients from bleeding led to a respect for the enormous potential for bleeding from aortic suture lines, which cannot be addressed easily or even seen at the end of this extensive operation. The routine use of aprotinin has helped eliminate this problem, but the strictest attention to gentle, accurate technique is still the most important factor.

The results of longitudinal echocardiographic follow-up are somewhat limited because of the difficulty of getting patients who feel so well to return for such studies. Of nine patients who were found to have moderate to severe AR, including the five patients who required reoperations, seven had AR as the original diagnosis, confirming the correlation of this preoperative diagnosis with subsequent failure of the operation found by Elkins and associates. ${ }^{8}$ We believe that careful attention to sizing and matching of the aorta to the autograft is particularly important in AR. As described in the Patients and methods section, supporting the anulus and the distal aortic suture line with circumferential Teflon felt strips should be a routine part of the operation when AR is the diagnosis. Potential autografts with a large, myxomatous valve should 


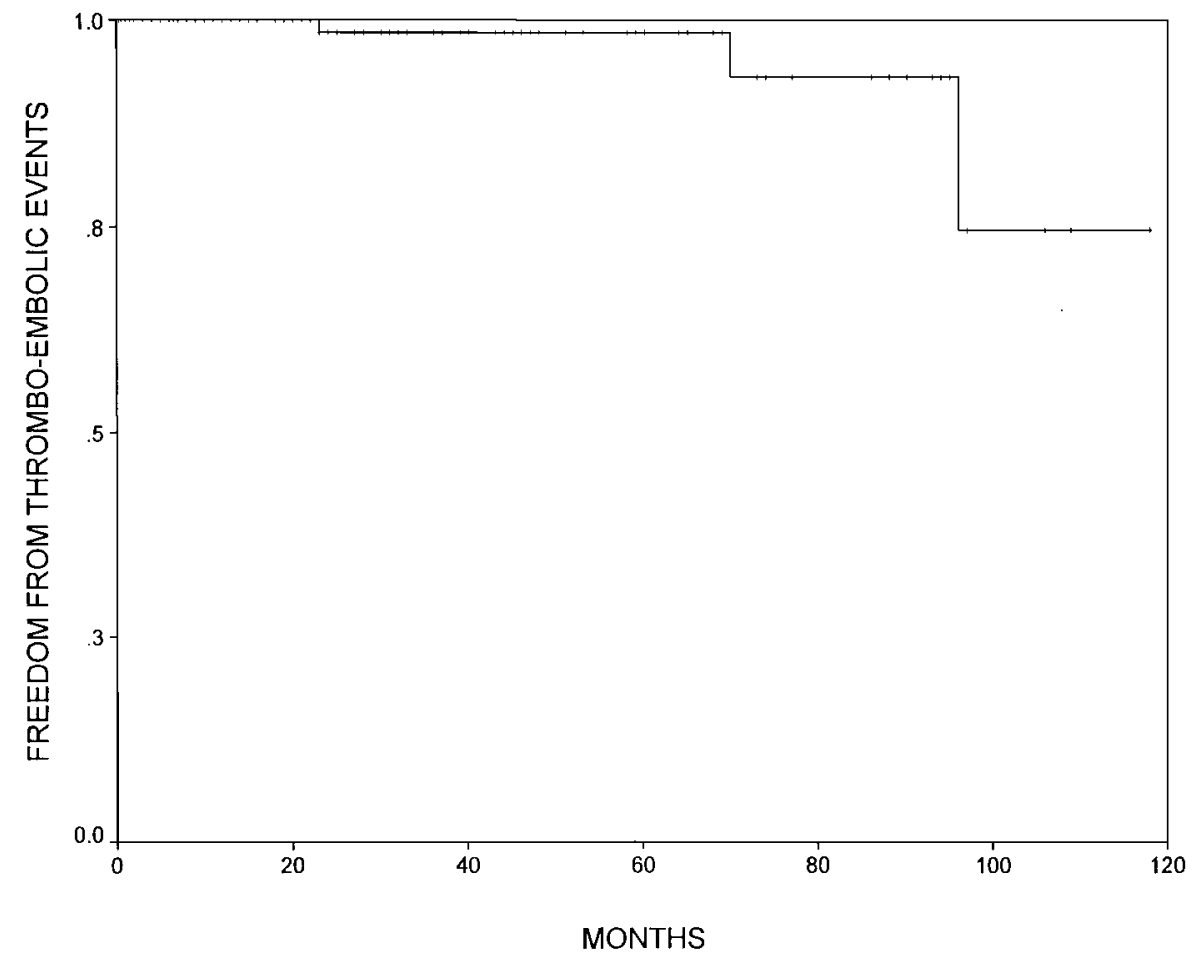

Fig. 3. Kaplan-Meier freedom from thromboembolic events.

not be implanted, but rather an aortic homograft should be used.

Although at least one third of patients have "dilated aortic root" reported on echocardiograms with dimensions of 3.7 to $4.2 \mathrm{~cm}$, we have not seen any progression of this root dilatation. However, serial echocardiographic data are too limited as yet to answer the important question of potential for such dilatation in the freestanding autograft root in the aortic position under systemic pressure after many years.

We are aware that there has been a small incidence of reoperation on the pulmonary homograft in the RVOT in other series, ${ }^{7,8}$ but so far this has not been required in any of these patients. We anticipate that eventual stenotic problems at the homograft valvular level might be addressed with balloon catheters. Similarly, pulmonary homograft insufficiency should be a lesion that can be very well-tolerated for many years as long as pulmonary artery pressures are low.

The group of 11 patients with active endocarditis had a high incidence of poor outcomes. Seven of them (63.6\%) had adverse events. Two were operative deaths, and one died suddenly at 2 years. Recurrent endocarditis developed in three patients, and two patients required reoperation. Combined renal and respiratory failure developed in one patient immediately after the operation. Also of note is that the entire incidence of postoperative endocarditis is derived from this group of patients with active endocarditis at the time of the original operation. Endocarditis has not developed in any other patient after the modified Ross procedure. Despite the desirability of the Ross procedure for all young patients and the success in this challenging group of infected valves reported by others ${ }^{16,17}$ we advise caution in selecting these very ill patients for such an extensive operation. Homografts may be preferable in these patients, especially in those with extensive annular abscesses.

This series is notably older than many other series, with a mean age over 40 years. The absence of pediatric patients is a reflection of the separation of adult and pediatric programs in New York State. As experience was gained with the procedure and because availability of aortic homografts was very 
The Journal of Thoracic and

Cardiovascular Surgery

Volume 115, Number 5

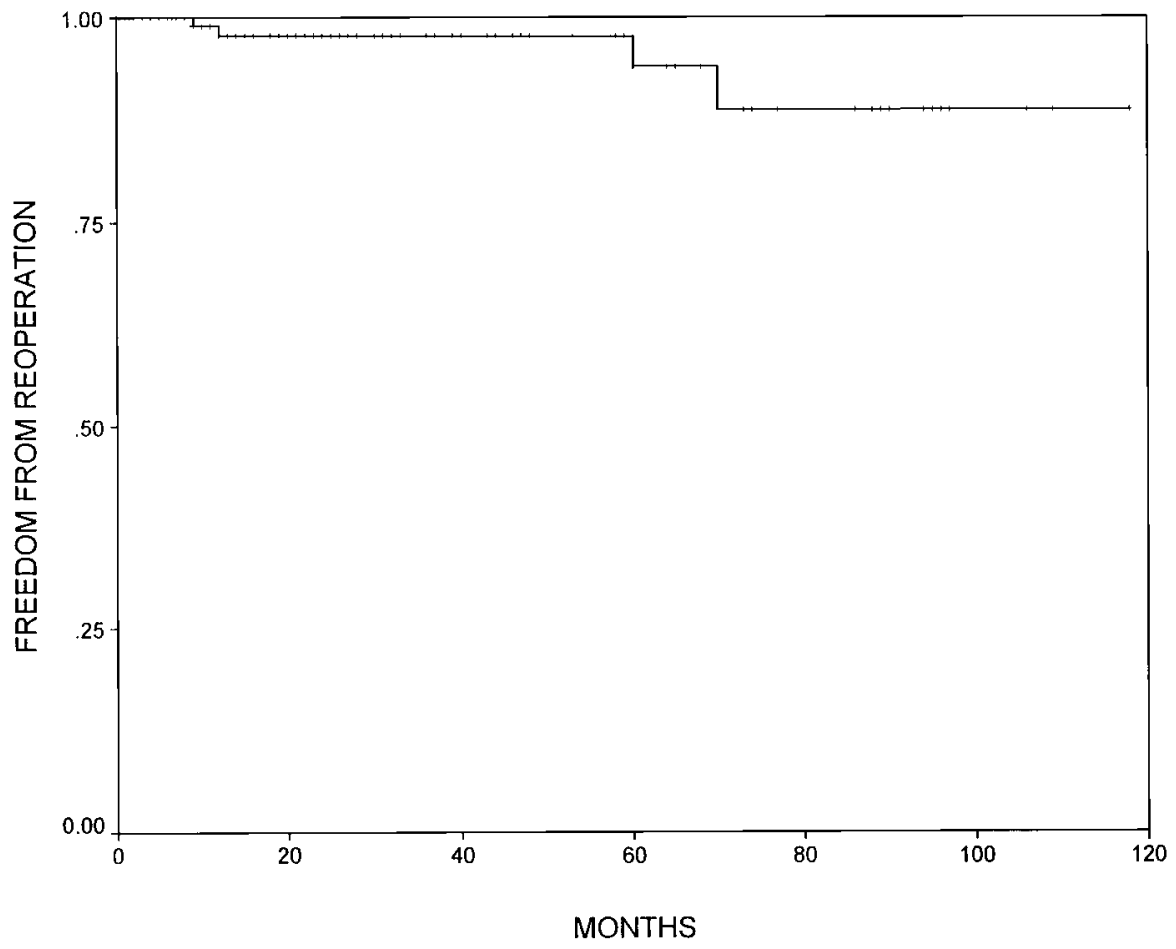

Fig. 4. Kaplan-Meier freedom from reoperation on the autograft valve.

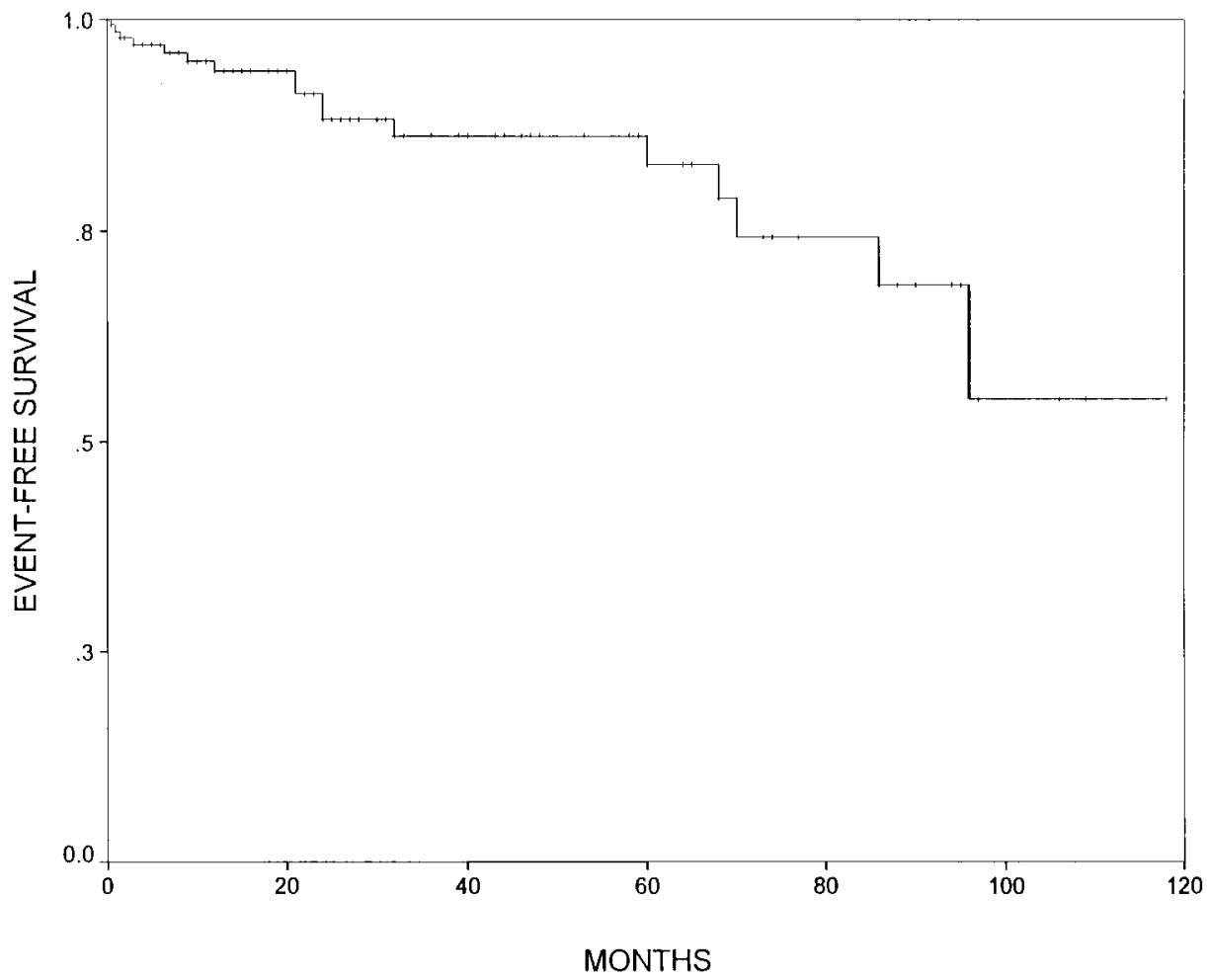

Fig. 5. Kaplan-Meier event-free survival. 


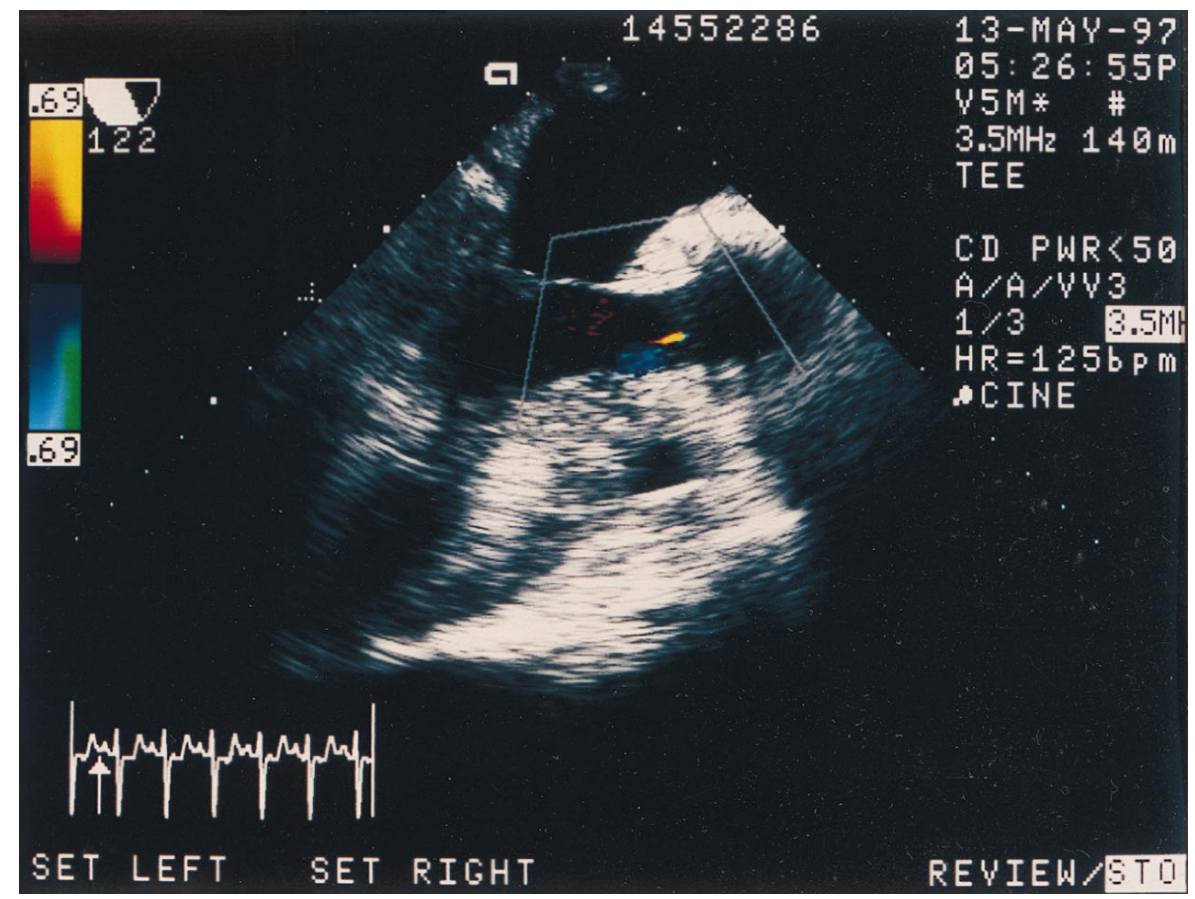

Fig. 6. Echocardiogram illustrates minimal central AR.

limited (especially in larger sizes), the operation was extended to older patients who were still believed to have a life expectancy of 25 years or more. Our current indications still use this benchmark of anticipated lifespan as a major criterion. The presence of extensive coronary disease should discourage the Ross procedure as a rule, but we believe that some coronary work with arterial grafts is justifiable. The patient with an unstable condition or the patient with severe left ventricular dysfunction does not tolerate this extensive operation well and should have a simpler valve substitute. Patients with concomitant mitral disease can be considered for this operation if the valve is repairable, especially if they are younger than 45 years of age. The presence of chronic atrial fibrillation would tip the scales in favor of mechanical valves in both positions. Marfan's syndrome is a contraindication to the Ross procedure, but a rare patient with ascending aneurysm not amenable to a valve-sparing operation might undergo the modified Ross procedure in combination with an ascending aortic graft. Because more elderly patients with mechanical valves experience thromboembolic and anticoagulant-related problems, our goal is to try to perform the
Ross procedure up to the age at which a standard tissue valve can be reasonably expected to outlive the patient.

\section{Conclusion}

In summary, our 10-year experience with the Ross procedure, modified by replacing the aortic root, has confirmed the suitability and safety of this operation for patients with aortic valve disease. It avoids anticoagulation and provides excellent hemodynamics, thus allowing unrestricted activity and lifestyle. There is a very low incidence of technical failure with this technique, which may be lowered even further with careful patient selection and attention to root tailoring and supporting elements. We conclude that the modified Ross procedure is the preferable operation for aortic valve replacement in younger patients but recommend caution in patients with active endocarditis.

We thank Mary Lane and Ronald Elkins, MD, at the University of Oklahoma Health Sciences Center for providing follow-up data on the first 15 patients in this series. We also thank Bertram I. Cohen, PhD, for statistical and technical support. 


\section{REFERENCES}

1. Ross DN. Replacement of aortic and mitral valves with a pulmonary autograft. Lancet 1967;2:956-8.

2. Ross D, Jackson M, Davies J. The pulmonary autograft: a permanent aortic valve. Eur J Cardiothorac Surg 1992;6: 113-7.

3. Ross D. Application of homografts in clinical surgery. J Card Surg 1987;1(suppl):175-83.

4. Stelzer P, Jones DJ, Elkins RC. Aortic root replacement with pulmonary autograft. Circulation 1989;80(Suppl):III209-13.

5. Stelzer P, Elkins RC. Pulmonary autograft: an American experience. J Card Surg 1988;3(suppl):313-9.

6. Stelzer P. Pulmonary autograft replacement of the aortic valve. In: Emery RW, Arom KV, editors. Aortic valve. Philadelphia: Hanley \& Belfus; 1991. p. 227-34.

7. Matsuki O, Okita Y, Almeida RS, McGoldrick JP, Hooper TL, Robles A, et al. Two decades' experience with aortic valve replacement with pulmonary autograft. J Thorac Cardiovasc Surg 1988;95:705-11.

8. Elkins RC, Lane MM, McCue C, Pulmonary autograft reoperation: incidence and management. Ann Thorac Surg 1996;62:450-5.

9. Oury JH. Clinical aspects of the Ross procedure: indications and contraindications. Semin Cardiovasc Surg 1996;4:328-35.

10. Kouchoukos NT, Davila-Roman VG, Spray TL, Murphy SF, Perrilo JB. Replacement of the aortic root with a pulmonary autograft in children and young adults with aortic-valve disease. N Engl J Med 1994;330:1-6.

11. Joyce F, Tingleff J, Pettersson G. A systematic technical approach to the Ross operation. J Heart Valve Dis 1996;5: 391-403.

12. Doty DB. Aortic valve replacement with homograft and autograft. Semin Thorac Cardiovasc Surg 1996;8:249-58.

13. O'Brien MF. Editorial: Aortic valve implantation techniques: Should they be any different for the pulmonary autograft and the aortic homograft? J Heart Valve Dis 1993;2:385-7.

14. Ross DN. Aortic root replacement with a pulmonary autograft: current trends. J Heart Valve Dis 1994;3:358-60.

15. Ross DN. Editorial: Reflections on the pulmonary autograft. J Heart Valve Dis 1993;2:363-4.

16. Oswalt J. Management of aortic infective endocarditis by autograft valve replacement. J Heart Valve Dis 1994;3:377-9.

17. Joyce F, Tingleff J, Aagaard J, Pettersson G. The Ross operation in the treatment of native and prosthetic aortic valve endocarditis. J Heart Valve Dis 1994;3:371-6.

\section{Discussion}

Dr. Donald B. Doty (Salt Lake City, Utah). Dr. Stelzer has presented a retrospective study of 145 patients who had aortic valve and root replacement using a pulmonary autograft, the modified Ross procedure. He operated on all of the patients himself. The initial 15 operations were performed in Oklahoma, and the subsequent 130 operations done in New York City. The results are excellent and speak for themselves. There are sufficient data in follow-up for Kaplan-Meier analysis at 7 or perhaps 8 years. Only four of the patients died early, 2.8\%, and significant complications occurred in only 12 patients, $8.5 \%$. Four patients required reoperation for incompetence of the pulmonary autograft in the aortic position, but two of those were infected. There were no reoperations for the pulmonary homograft in the pulmonary position. Stelzer provided a significant advance in our understanding of the Ross procedure by performing the transfer of the pulmonary valve to the aortic position by using the entire pulmonary trunk. The operation is a total, free-standing aortic root operation and provides two important technical aspects. One, complete removal of all aortic root components that are abnormal, and two, using the intact pulmonary trunk in the aortic position offers the best chance to eliminate distortion of the pulmonary valve. $\mathrm{He}$ is also a proponent of external support and fixation of the pulmonary trunk by incorporating a Teflon or pericardium support collar at the proximal suture line in the left ventricular outflow tract.

I agree completely with all of the points that Dr. Stelzer has made and will reiterate some of them for emphasis Preventing failure in the Ross operation is accomplished mainly if not entirely by meticulous attention to technical detail. Transferring the pulmonary trunk as a complete, free-standing root into the aortic position seems to offer the best chance for achieving an undistorted pulmonary valve. Size discrepancy between the aortic root and the pulmonary trunk should be corrected by adjustment of the size of the aortic root. The aortic root may be reduced or enlarged, using established techniques to match it perfectly to the size of the pulmonary trunk. The pulmonary trunk is flexible, distensible tissue and can be molded to any size by constricting it in a suture line or stretching it over an enlarged left ventricular outflow tract. Such practice should be avoided because it may significantly affect the apposition of the pulmonary valve cusp. A supported root technique in which a Teflon felt or pericardial ring is incorporated in the proximal suture line appears to reduce the chance of dilation of the pulmonary valve when subjected to systemic pressure. The support ring also reduces bleeding. It should be recognized that this operation requires multiple sutures and suture lines that are all exposed but that are not readily accessible, even on cardiopulmonary bypass.

I agree with Stelzer that the application of the Ross procedure in patients with bacterial endocarditis that is extended off the aortic valve cusp into adjacent tissues with aortic root abscesses should be avoided. The Ross operation opens more tissue planes and adds excessive operating time for patients in whom sepsis syndrome will persist for several hours after the operation. Aortic root replacement with cryopreserved homograft is an established operation that is preferred in this setting. The Ross operation takes more time than usual aortic valve replacement. In spite of the extra time of cardiac ischemia and on cardiopulmonary bypass, the patients recover rapidly and spend only 4 to 5 days in the hospital. Perhaps this is related to the optimal hemodynamic performance associated with the Ross procedure. Exercise performance after operation is especially impressive, making this operation helpful to athletic individuals.

Now that you have enlightened us as regards the results at 10 years after aortic valve replacement with pulmonary autograft, would you care to speculate on what we can anticipate between 10 and 20 years after this operation?

Dr. Stelzer. Looking to the future in answer to your question, let me direct to two points. The autograft-I am 
convinced that if you put it in right, support it properly, and have a competent valve, when you leave the operating room, the chances are very good that this is going to last for the patient's natural lifetime. The pulmonary homograft in the RVOT then becomes the limiting factor. There has a been a low incidence of reoperation for stenosis of that conduit, usually at a very early time, perhaps on an immunologic basis. I have been fortunate that I have not had to do that yet, but it has happened in $1 \%$ or $2 \%$ of people. Because the aortic homograft in the RVOT, in Ross's hands, has somewhat in the range of $75 \%$ freedom from reoperation at 25 years, we have an even better likelihood of the pulmonary homograft (having less intrinsic calcium and thickness) lasting longer. However, if those leaflets become stiff, calcified, stenotic, surely they can take a balloon up there and blow it away. Transcatheter techniques might be able to extend its life considerably longer without reoperation; and if it becomes incompetent at that point or gradually at that point (or becomes so gradually), we know that people can tolerate wide-open pulmonary insufficiency for 15 or 20 years before they get right ventricular dilatation and perhaps exercise-induced arrhythmias, as some of the children who have had pulmonary valvectomy have demonstrated. This gives me hope that we may be able to get 30 or 40 years out of that RVOT reconstruction, which means most of these folks will only have to have one more procedure done on the RVOT, which is a lot easier to do than redoing the aortic. That is my optimistic look at the future. It has been gratifying to see people like Dr. Doty and a number of others confirm my experience that the total root replacement is not only a reproducible way of providing a competent valve, but it is also teachable, learnable, and reproducible in hands other than just mine. I think longer follow-up of patients is necessary to confirm these findings that there is a significant advantage of the full root over the intraaortic techniques as first reported by Ron Elkins last year at the Society of Thoracic Surgeons meeting, and this experience confirms that.

Dr. Frederic Joyce (Albany, N.Y.). Anyone who has done a Ross operation and has seen how thin the autograft is and has thought about putting it into a highpressure system as a free-standing aortic root is a brave person, and you did it first. It is a brave step, but a logical one, because you are maintaining the three-dimensional characteristics of the pulmonary valve. But that does not happen automatically, and I am glad that Dr. Doty discussed a little bit about the sizing issues. Would you comment on how you deem a pulmonary autograft satisfactory size-wise for what you are going to be inserting it into? In our work, we have looked a lot at the pulmonary root sinotubular junction and used that as our major defining dimension and related that to the aortic anulus. I was wondering if you would comment on that. As far as your conclusions on endocarditis, I disagree, but we will be hearing more about that tomorrow.

Dr. Stelzer. In regard to the sizing issue, I think that 2 to $3 \mathrm{~mm}$ of difference between the pulmonary root and the aorta can be made up pretty well just by incorporating a cuff of Teflon fabric. I traditionally measure the pulmonary anulus just hanging limp there with a sizer, a standard sizer. If it is a 25 , let's say, then I will take a 27 sizer, wrap a Teflon strip around it, and cut that to size, so I know that I have got one size bigger strip of Teflon on the outside and that is what I incorporate. If there is more than $5 \mathrm{~mm}$ difference, and usually this is bigger aorta than pulmonary, I plicate the commissures, the trigones, especially between the left and the noncoronary sinus, and bring it down at that point to a size that is down to the 2 to $3 \mathrm{~mm}$ or equal, and then incorporate the cuff on top of that. That is the way I handle the sizes. More than a centimeter bigger, I do not think you should do it; I think that is just a little bit too much to make up.

About the endocarditis issue, I am looking forward to hearing your paper, and I am glad you have had better experience than I. I am having to report what I experienced, and I must acknowledge that those two people who died were in the first 15, that may have been a learning curve and I was pushing the envelope a bit, and so that may have had something to do with it. Those are the data, and I wanted to present that.

Dr. D. Craig Miller (Stanford, Calif.). As counterpoint to some of the enthusiasm that Dr. Doty and Dr. Joyce and you have shared with us, and I know there are other "Ross zealots" in the audience, some of whom do Ross operations in patients of almost any age, let me tell you what is going on at the Cleveland Clinic. Three weeks ago, Dr. Cosgrove stated publicly in Boston that broad use of the Ross procedure at the Cleveland Clinic is basically over. Their results may be just as good as Dr. Stelzer's, but failures of both the autograft and the pulmonary homograft appear to have tempered his enthusiasm for this procedure. Dr. Cosgrove currently believes that these young patients really should not have to face this chance of reoperation. Do you have any comments pertaining to Dr. Cosgrove's current posture that the Ross procedure is not all a bed of roses?

Dr. Stelzer. I have not seen his reports and have not talked to him lately, but I am glad he has not tried to do this minimally invasively (laughter); but you know, I can get these folks home quickly, some of them on postoperative day 3 , so I think I can justify staying with the median sternotomy. (It has been done minimally invasively in Berlin now by Konertz.) I do not know what the problems are that they are encountering in Cleveland. Dr. Doty has certainly pointed out that you must pay meticulous attention to detail; this is not an operation in which the attending surgeon can drop in for an hour and be gone. 